\title{
Positioning Urban Neighborhoods for Prosperity
}

\author{
MO ZELL \\ University of Wisconsin-Milwaukee
}

\begin{abstract}
Globally, financial and cultural pressures continue to contribute to localized inequalities. These growing disparities generated by real estate speculation and migrations tend to intensify rather than abate a sense of inequality and the undoing of communities. In Milwaukee, however, the problem is the opposite. Gentrification due to real estate speculations do not exist in the same degree. Instead, systemic poverty contributes to the disenfranchisement of black and brown populations. Empty storefronts in neighborhoods hit hard by poverty are not being replaced with high-end condos, but rather they simply remain empty. This paper details the efforts to ameliorate not only the physical attributes of vacancy through changing capital flows but also to give agency to voices from the community.
\end{abstract}

In 2014, the UWM School of Architecture and Urban Planning started a pop-up gallery called the Mobile Design Box to display the design projects from students at the School in an empty storefront space in Milwaukee for a few months. The impetus for project stemmed from the work created during the Marcus Prize studio. Not only did the school have a collection of large-scale posters from an internal exhibit by Marcus Prize winner Sou Fujimoto, it had a second exhibition of design work including models and drawings from the students in the Marcus Prize studio. A book was also being planned. In an effort to extend the life of the studio and leverage the significant work completed, SARUP partnered with a local developer with available empty storefront space to house an off-campus School gallery.

At the time, the gallery would provide 3 things -1 ) visibility in the community to showcase the innovative research from the studio 2) highlight the partnerships developed during the studio, and 3) provide a venue for the creation of the Marcus Prize Studio book. A storefront space would provide a visible legacy for the project extending its impact to new audiences. At the last minute the School added a 4th provision - a creative entrepreneur partner to share exhibition space in the gallery. This partnership changed the course of the Mobile Design Box.

What was meant as a simple pop-up gallery temporarily occupying vacant storefront space in downtown Milwaukee turned into a form of tactical urbanism - a method of disruption to the status quo for both the University and the City. For the University, leaving the confines of the campus is a major disruption to the top down bureaucracy of state run institutions while the University, in turn, disrupts the natural order of urban real estate development by acting as an intermediary for short term leasing opportunities.

In the book The Temporary City, Peter Bishop and Lesley Williams describe tactical urbanism as having a reciprocal relationship between the economy and urban vacancy. Khaliff Davis, in his paper titled 'Can Pop-Up Shops Improve My Community' distills their research by stating "the obsolescence of post-industrial sites and the impact of the economic crisis on private and public investment have produced an abundance of vacant property. The availability of urban vacancies proves significant in allowing temporary activities to unfold." ${ }^{1}$ All three researchers conclude that tactical urbanism provides bottom up community engagement strategies that look to improve distressed neighborhoods. Vacancy is converted from a liability into an opportunity by the introduction of activities and programming.

Neil Brenner, in his essay from 2015 "Is 'Tactical Urbanism' an Alternative to Neoliberal Urbanism?" summarizes the term tactical urbanism from contributors to the MOMA exhibition "Uneven Growth: Tactical Urbanisms for Expanding Megacities" as a framework of experimental or provisional urban projects organized as a bottom up strategy (although not precluding work with top down entities like government, developers, and corporations) with pinpoint interventions pertaining to local issues but whose process of activation is both malleable and metamorphic. Brenner's summary of the term as "an acupunctural, participatory, open-sourced intervention"2 highlights a process of community engagement that is at the core of many bottom up faculty initiated strategies for the city and in particular for the transformation of the Mobile Design Box from a passive repository of pictures into a generator of new forms of community engagement and entrepreneurship for Milwaukee.

Milwaukee is experiencing unprecedented development in downtown, but the benefits of which is not extending to economically vulnerable communities on the outskirts of downtown. Construction of the Northwest Mutual tower in downtown Milwaukee, completion of the new Milwaukee Bucks basketball arena and the downtown streetcar are all examples of public and private investment in the downtown core. These investments, manifest in large-scale buildings or major road construction, are visibly accessible. 


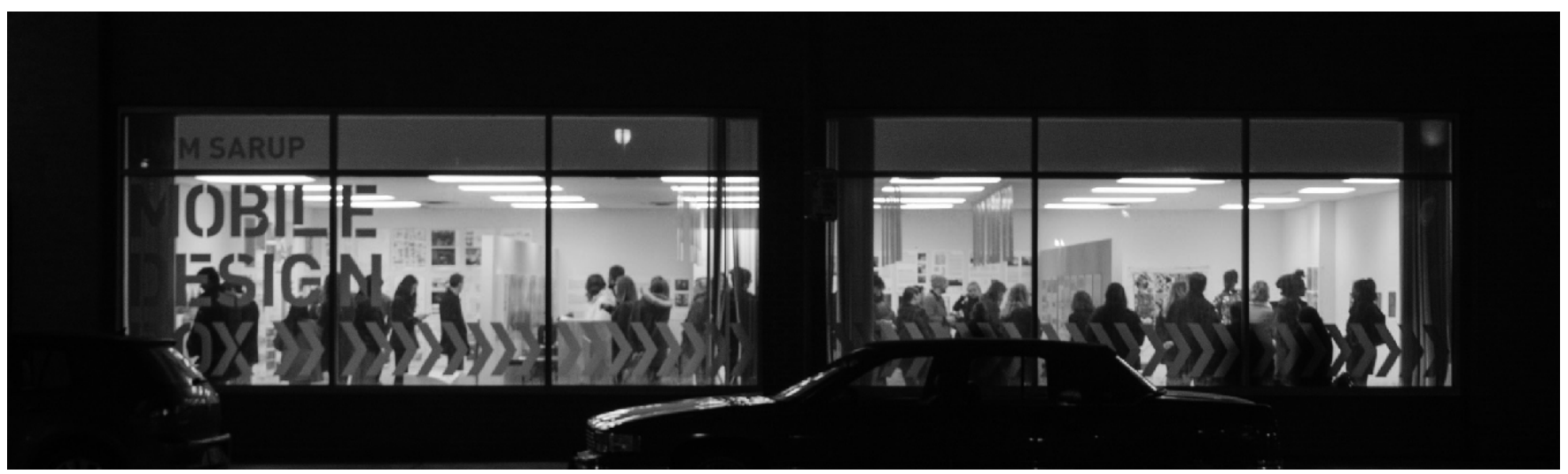

Figure 1: MDB on Gallery Night. Gallery night serves to launch every creative exhibitor in the space on a 4 month cycle. Photo by Eli Liebenow

Outside Milwaukee's downtown core are transitional 'middle landscapes', ones in which traditional neighborhood commercial corridors are struggling to redevelop not only a physical identity (filling in missing teeth) but also finding opportunities for additional economic investments. This context is juxtaposed between the tight knit urban fabric of downtown and the less dense residential urban landscapes found further from downtown.

In these middle landscapes, where middle class families relied on manufacturing for well paying jobs, the conditions of poverty outlined in Matthew Desmond's book Evicted also play out. Therefore, it is with this context in mind that we have found new opportunities and new partnerships for temporary urban actions through an updated version of the Mobile Design Box in which vacancies shift from a liability into an opportunity.

Bishop and Wiliams state that "in an era of increasing pressure on scarce resources, we cannot wait for long-term solutions to vacancy or dereliction. Instead, we need to view temporary uses as increasingly legitimate and important in their own right." ${ }^{3}$ As a temporary urban action, the Mobile Design Box was originally initiated in 2014 as a partnership between the School and a single developer with no other community partners. The Mobile Design Box (MDB) occupied a raw, industrial space rent and utility free.

In University terms, the MDB was an unfunded mandate spearheaded by a single faculty member. There was no capital for the project other than minimal support for the gallery night reception (and over time even this disappeared). Therefore exhibitors had to invest their own funds to create their exhibits.

In addition to the gallery night kick off events, it was critical that the exhibitors create additional programming and advertising within their personal communities to generate the audience. We had a range of success with this including $A R C H$
810: Architectural Design I Final Review, Cinema Sundays, In-Motion Mondays, 50 x 50 Design + Dinner, Friday Night Films, and Piñata Playtime.

What became clear from operating version 1 of MDB was that we wanted and needed a community partner to enhance the engagement of the surrounding community and shift a top down, outsiders perspective, into one where the space could be a community asset. And thus through a community engagement process with specialist from the city, neighborhood groups, arts groups and community BIDS we strategically selected three commercial corridors to focus our effort and then picked one of those as the next neighborhood for the Mobile Design Box.

Each neighborhood under review underwent a resident engaged planning process for redevelopment that was aligned with several comprehensive commercial corridor plans articulated within a citywide initiative called MKE United. This action plan worked to ensure that investments extended from downtown into neighborhood corridors towards a more inclusive and vibrant community. Arts and cultural programs are a strategy embraced across the three selected neighborhoods as a way to demonstrate pride and strengthen the social and economic vitality of the corridors. The process oscillated between grassroots initiatives and more traditional urban planning procedures.

Key objectives for the neighborhood partners were to attract investment in commercial corridors and reduce vacant properties; improve the quality of life for residents; make each corridor safer and change negative perceptions; attract new tenants and potential investors; provide high-quality arts, and opportunities for civic engagement for residents; build social cohesion and strengthen the unique identity of each corridor, while one of the School's objectives was to connect architecture and planning students to real world projects and venues for community engagement. 


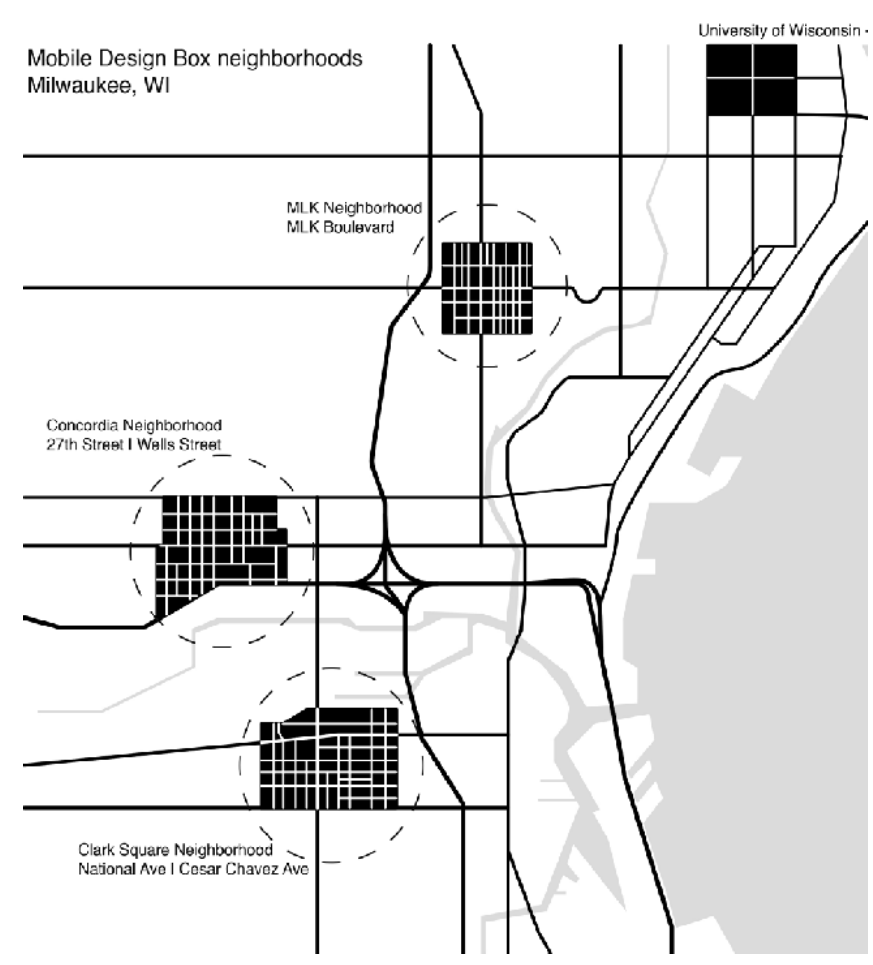

Figure 2: City map locating Mobile Design Box(es) in three neighborhoods.

The MDB version 2 partnership, occupying a site in the Concordia neighborhood, is a complex relationship between a community organization, the Near West Side Partners (NSWP), a local architecture firm that does pro bono work with the NWSP, the developer (who also has a professional relationship with the architecture firm), and the School.

The New West Side is made up of seven unique neighborhoods, each with its own history. Nearly 30,000 people live in the NWS, including 10,000 university students. Over $50 \%$ of the population is below the poverty level. 2015 Median household income for the area was under $\$ 20,000$. However, the area is seeing increasing investment, with more than $\$ 250$ million invested over the past 5 years in institutions, housing and commercial development. Although a large portion of that is limited to Marquette's campus. Five major anchors in the neighborhood, Marquette University, Aurora Health Care, Harley-Davidson, Miller/Coors and Potawatomi Business Corporation contribute to the work force in this neighborhood and fund the NWSP organization.

Our partnership with the developer includes occupying storefront space inside a block of buildings that once housed a hospital, office building and theater space. We have access to three bays of the glazed storefront and the internalized theater foyer for programming. The developer is in the process of renovating the other parts of the building.
In collaboration with the NWSP and the local architecture firm we have built a coalition of programming partners that include local residents, BIDS, arts organizations, individual artists, and cultural institutions. These partners use the space as a pop-up. Occupying the space on a shorter term than the 4 month gallery cycle, these programming partners operate within the exhibitors spaces - using the exhibitor displays as the backdrop to their events.

Programming has included events curated by the local chapter of the national group Creative Mornings, a monthly pop-up networking venue for creative voices, Conference Break Out sessions, Women in Design Pecha Kucha Events, Spoken Word Youth Outreach Initiatives, Artist workshops, Historic Home Tours, City DCD community meetings, AIA Milwaukee Board Meeting, a pop-up restaurant, and a Summer Residency program, led by artist Kirsten Leenaars and her young collaborators tackling global issues at the local scale.

(Re)Housing the American Dream: A Message from the Future was commissioned by Marquette University's Haggerty Museum of Art. Structured annually as a three-week summer camp - the 2017 iteration was based in the MDB. The project provided a collective forum for refugee and American-born children to engage critically with the intersecting issues of immigration, segregation, housing, and happiness. MDB served as a venue to visualize voices these youth voices in the community. The artists and her students not only activated the space for 3 weeks but they activated the streets surrounding the MDB extending programming into the public realm.

When financial capital is limited other forms of assets become important commodities. The Mobile Design Box offers three: available space, partners in marketing, and short term stays. By operating as part of the University, the School leverages its nonprofit status and philanthropic relationships to find the developers with vacant storefronts to partner on the project. In turn, the School acts as an intermediary to host exhibitors and pop-up programming. Given the rent free status, and the short term occupation of the space (spending under 4 months in the space as dictated by the gallery night schedule) exhibitors can focus capital investments on the exhibition of the work and building their own set of partnerships to further business opportunities.

Panu Lehtovuori and Sampo Ruoppila in their essay "Temporary Uses as a Means for Experimental Urban Planning" state that "in order to flourish, non-profit projects as well as beginning companies require availability of affordable spaces, which the 'pioneering' activists search for." ${ }^{\prime 4}$ The MDB serves as this platform in Milwaukee. The costs and time associated with temporarily occupying vacant storefront space is still at a premium for nascent creative entrepreneurs. A mediator, like the MDB, fills this gap in the market. Over the 4 years since its inception exhibitors in the 


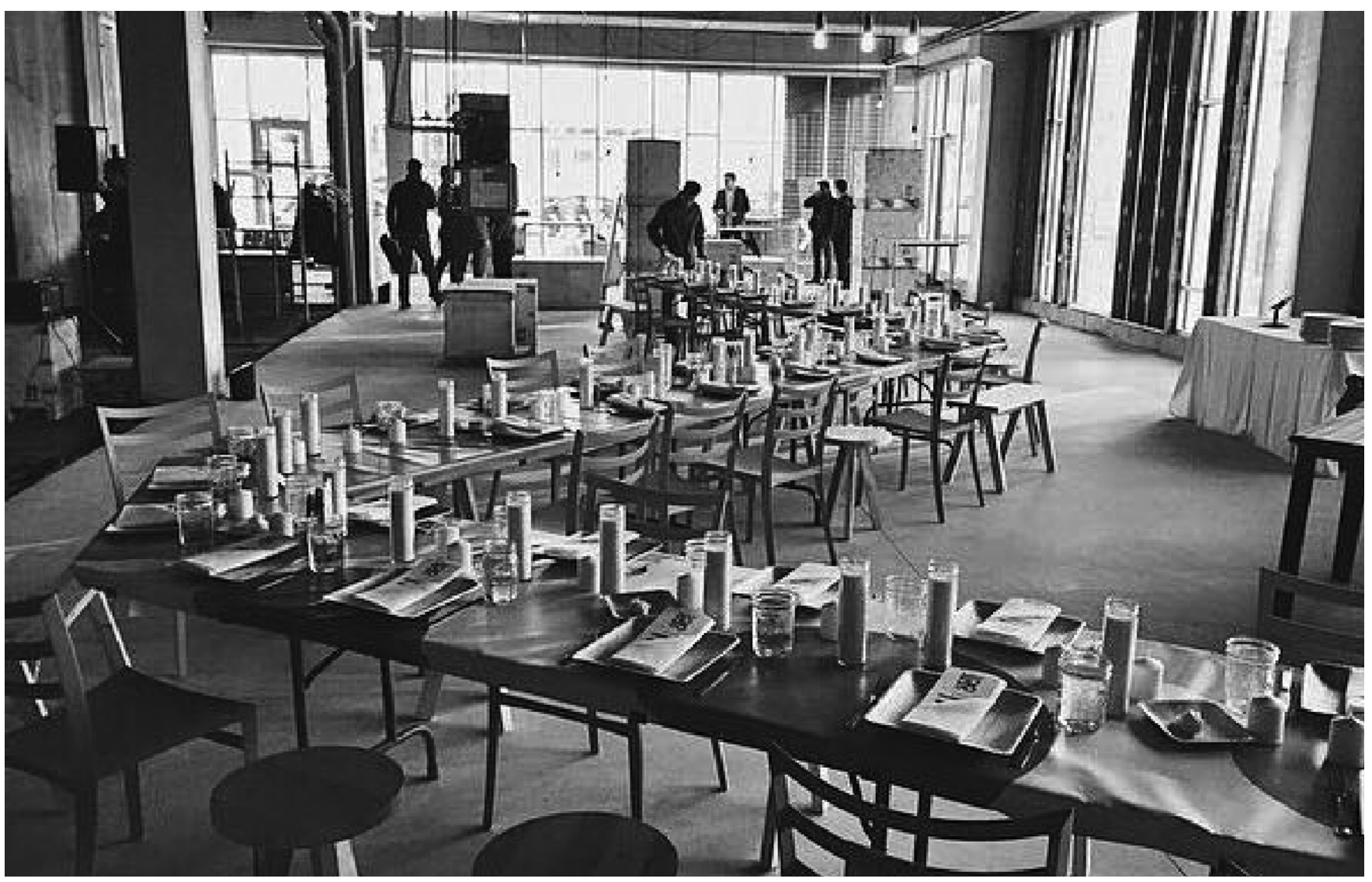

Figure 3: 50x50 Dinner and Design event curated by creative entreprenuer partner Ryan Tretow inside the North End Mobile Design Box.

MDB have launched two creative businesses, generated over $\$ 50,000$ in direct fees and stimulated over $\$ 250,000$ of economic development.

Although the model has been successful and we continue to engage with our partners in the two other commercial corridors, starting our 2 nd and 3rd neighborhood MDB's has been slow. By expanding into additional neighborhoods, the MDB has the potential to build its own identity and therefore attract new first time users into not just one space but a series of spaces across the middle landscape outside the city center. The MDB brand can provide consistency as temporary users move in and out of the spaces on the Gallery night cycle. Over time, this longevity can be leveraged for larger scale projects that connect across the city not just within neighborhoods.

In areas of the city that are in decline the Mobile Design Box enhances the quality of neighborhood space and urban life through the activation of a vacant storefront into a community space and creative entrepreneur start up venue. As a framework, the MDB operates as host to a series of temporary users who in turn are host to more temporary uses. Given that the Milwaukee gallery night cycle sets not only the timeline for temporary users but also uses art as the capital for exchange, the MDB incubates creative entrepreneurs looking for opportunities to expand or start their creative businesses. The MDB is not the gallery itself, it is a localized restructuring of the flow of capital from tenant to landlord that optimizes short term leases with low overhead, minimal investment and maximized effort to engage local communities.

\section{ENDNOTES}

1. Khaliff Davis, "Can Pop-Up Shops Improve My Community: Exploring the Linkages between Tactical Urbanism and Community Development," Masters Project, Georgia Institute of Technology (May 2015).

2. Neil Brenner, "Is 'Tactical Urbanism' an Alternative to Neoliberal Urbanism?" MoMA's "Post" online resource, March 24, 2015, http://post.at.moma. (1) al-urbanism.

3. Peter Bishop and Lesley Williams, The Temporary City (London: Routledge, 2012).

4. Panu Lehtovuori and Sampo Ruoppila, "Temporary Uses as a Means of Experimental Urban Planning" SAJ 4, no. 1 (2012): 34. 